\title{
Yapay Sinir Ağları ile Trafik Yoğunluğu Tahmini*
}

\section{Traffic Density Estimation with Artificial Neural Networks}

\author{
Arş. Gör. Nurullah TAŞ (iD) 1 , Prof. Dr. Bülent SEZEN (D) 2
}

\begin{abstract}
$\ddot{O} z$
Şehirlerin büyük problemlerden olan trafik yoğunluğu, insan hayatını birçok yönden etkilemektedir. Daha yaşanabilir bir kent hayatı için; mevcut yoğunluğun belirlenerek araç trafiğinin kontrol edilebilmesi ve ileride yaşanabilecek sıkışıklıklar için gerekli önlemlerin alınabilmesi gerekmektedir. Trafik yoğunluğunu arttırabilecek muhtemel parametreler dikkate alınarak gerçekleşecek bir yoğunluk tahminin, kent sakinleri açısından olduğu kadar sürücüler ve bir şehrin mümkün olan en az trafik yoğunluğuna maruz kalmasından sorumlu olan yetkili kurum ve kuruluşlar için önemli bir yeri vardır. Çalışma, İstanbul' a Tuzla ilçesinden giriş yönünde, E-5 karayolu üzerinde yapılmıştır. Veriler, Yandex Trafik ve Wunderground internet sitelerinden elde edilmiştir. Hafta içi günler, mesai saatleri, havanın genel durumu, sıcaklık, rüzgârın hızı ve nem seviyeleri bağımsız değişken olarak alınmıştır. Gün, saat ve hava koşulu değişkenleri kategoriktir ve bu değişkenler kukla değişken olarak belirlenmiştir. Bağımsız değişkenlerden hareketle hız tahmini yapılmış ve trafik yoğunluğu seviyesi belirlenmeye çalışılmıştır. Diğer bağımsız değişkenlere kıyasla, rüzgar hızı ve sıcaklık değişkenlerinin hız üzerinde negatif ve yüksek oranda etkili olduğu, olası bir değişiklik durumunda sıcaklığın hızı en yüksek düzeyde etkileyeceği görülmüştür. İlgili güzergahta genel olarak $80 \mathrm{~km}$ ortalama hız düzeyi elde edilmiş ve Serbest Akım Hızı, C ve D hizmet seviyeleri için incelendiğinde, en fazla yoğunluk düzeyinin 16- 22 aralığında, en fazla hacim/ kapasite oranının \% 64- 85 aralığında olacağı tespit edilmiş̧tir.
\end{abstract}

Anahtar Kelimeler: Trafik yoğunluğu, araç hızı, hava koşulları, çalışma zamanı, yapay sinir ağları

Makale Türü: Araştırma

\begin{abstract}
Traffic density, which is one of the major problems of cities, affects human life in many ways. For a more livable urban life, by determining the current density, it is necessary to control the vehicle traffic and take necessary measures for future congestion. An estimation of density to be made taking into account the possible parameters that may increase traffic density has an important place for drivers and authorized institutions and organizations responsible for exposure of a city to the least possible traffic density for city residents. The study was carried out on the E-5 highway in the direction of entrance from Tuzla district to Istanbul. The data was obtained from Yandex Traffic and Wunderground websites. Weekdays, working hours, general condition of the weather, temperature, wind speed and humidity levels were taken as independent variables. Day, hour and weather conditions are categorical and these variables are determined as dummy variables. An average speed level of $80 \mathrm{~km}$ was obtained on the relevant route, and when Free Flow Speed was examined for $\mathrm{C}$ and $\mathrm{D}$ service levels, it was determined that the highest density level would be in the range of 16-22, and the maximum volume / capacity ratio would be in the range of $64-85 \%$.
\end{abstract}

Keywords: Traffic density, vehicle speed, weather conditions, working time, artificial neural networks

Paper Type: Research

\footnotetext{
* Bu çalışmanın, analiz içermeyen literatür kısmı, 21.06.2019 tarihinde İstanbul'da düzenlenen III. Uluslararası Stratejik ve Sosyal Araştırmalar Sempozyumu (ISASOR III-2019) kongresinde sözlü bildiri olarak sunulmuştur. Çalışma, daha sonra genişletilmiş olup son şekli ile, 27.07.2020 tarihinde, Gebze Teknik Üniversitesi Sosyal Bilimler Enstitüsünde Yüksek Lisans Tezi olarak sunulmuştur. ${ }^{1}$ Gebze Teknik Üniversitesi, İşletme Fakültesi, nurullahtas@gtu.edu.tr.

${ }^{2}$ Gebze Teknik Üniversitesi, İşletme Fakültesi, bsezen@gtu.edu.tr.
}

Atıf için (to cite): Tas, N. ve Sezen, B. (2020). Yapay sinir ağları ile trafik yoğunluğu tahmini. Afyon Kocatepe Üniversitesi Sosyal Bilimler Dergisi, 22(4), 1020-1034. 


\section{Giriş}

Şehirlerin sürdürülebilir bir hayat standardı ve ekonomik kalkınma düzeyine erişebilmesi için gerekli şartlardan birisi de yaşam alanlarını birbirine bağlayan karayollarında bir düzenin, bu düzen içerisinde de mümkün olan en az sorunla akan bir trafik ağının oluşturulması gerekmektedir.

Hız, karayollarında yoğunluğa sebep olan etkenlerden birisidir. Gerek sürücü tercihlerinin sonucunda gerekse de trafik kurallarından ya da diğer etkenlerden kaynaklı olarak araçların hızları az ya da fazla olabilmektedir. Hızdaki bu az ya da fazlalık, trafik akış seyrine etki etmekte, bu da yoğunluğa ve yoğunluk derecesinin seviyesinde değişikliğe neden olmaktadır. Ayrıca, yoğunluk; trafikteki kaza ve araç sayısı; sıcaklık, yağış, hava durumu gibi meteorolojik olaylar; yolun altyapı özellikleri; trafik talebinin artma gösterdiği gün ve saat, tatil dönemi olup olmaması; sürücülerin tecrübe durumu ve araçların karakteristik özellikleri gibi faktörler tarafindan etkilenmektedir.

Nedenleri ve meydana getireceği sonuçlar dikkate alındığında, özellikle büyük insan kalabalıklarının yaşadığı İstanbul gibi büyükşehirlerde, araç trafiğinin kontrol altına alınmasının önemi artmaktadır. Mevcut sıkışıklık düzeyinin tespiti ile belirlenecek seviye, buna neden olan temel nedenlerle birlikte kontrol altına alınmalı ve bu yoğunluğu önleyecek güncel ve muhtemel tedbirler uygulanmalıdır.

Çalışma İstanbul' da; sıcaklık, nem, rüzgar hızı, hava koşulları gibi meteorolojik faktörler; trafik talebi üzerindeki etkileri nedeniyle gün ve ilgili günlerdeki mesai saatleri değişkenleri dikkate alınarak yapılmıştır. Çalışmaya dahil edilen bağımsız değişkenler ile araçlara dair hız tahmini yapılmış ve bu hız değerleri üzerinden yoğunluk değerlendirmesinde bulunulmuştur.

\section{Literatür Taraması}

Andrey vd. sürücülerin kötü hava şartlarına adapte olmalarını araştırdıkları çalışmalarında, sürücü davranışlarının karlı ve yağmurlu havalarda özellikle sorunlu olduğu belirtmiş̧lerdir (Andrey, Hambly, Mills, \& Afrin, 2013). Abdel-Ayt vd. tarafından yapıla çalışmada ise, sis ve duman nedeniyle meydana gelen kazalardaki yaralanma şiddetini tahmin etmeye çalışmışlar ve sonuç olarak; net görüş koşullarındaki çarpışmalarla karşılaştırıldığında, sis ve duman koşullarında meydana gelen çarpışmaların, daha ciddi yaralanmalara yol açma eğiliminde olduğu görülmüştür (Abdel-Aty, Ekram, Huang, \& Choi, 2011). Yan vd. tarafından yapılan çalışmada, farklı risk düzeylerinde sürücülerin, sisli havalardaki sürüş riskini düşürmek için hızlarını düşürdüklerini tespit edilmiştir (Yan, Li, Liu, \& Zhao, 2014). Cools vd. yaptıkları çalışmalarında; yağışlar ve rüzgar hızının trafik yoğunluğunu azalttığını, yüksek sıcaklıkların ise yoğunluğu arttırdığını belirtmişlerdir (Cools, Moons, \& Wets, 2010). Datla ve Sharma, soğuk hava ve kar yağışının trafik hacmi üzerindeki etkisinin gün, saat ve yol türüne göre farklılaştığını, tüm yol tipleri için ise, kar yağışının trafik hacminde bir azalma göstergesi olduğunu belirtmişlerdir (Datla \& Sharma, 2008). Nofal ve Saeed çalışmalarında; sıcaklığın stres oluşturduğunu ve sürücü performansını düşüren bir faktör olduğu öne sürmüştür (Nofal \& Saeed, 1997). Cools vd. günlük araç sayısı farklılaşmasının haftalık periyotlarla izah edilebileceğini ve tatil dönemlerinde yoğunluğun dikkate değer bir düzeyde azaldığını tespit etmiş̧lerdir (Cools, Moons, \& Wets, 2007). Keay ve Simmonds ise, yağmurun gece ve gündüz zaman dilimi için ortalama kaza sayısında artışa neden olduğunu tespit etmişlerdir (Keay \& Simmonds, 2005). Unrau ve Andrey, hacim- doluluk ve hız- hacim ilişkilerinin yağışlardan etkilendiğini ve hızın hacme güçlü bir şekilde bağlı olduğunu belirtmiş̧lerdir (Unrau \& Andrey, 2006).

\section{Ulaşım ve Trafik Mühendisliği}

Ulaşım; yararlı bir maksat uğrunda, şahıslar veya eşyaların yer değiştirmesidir. Ulaşım olayı ile gerçekleşen yer değiştirme faaliyetine de ulaştırma ya da taşıma denilmektedir. Ulaştırma; kara (karayolu- demiryolu), su (denizyolu, iç su yolu), hava ve boru hatları diye altyapı 
özelliklerine göre dallara ayrılmaktadır. Gerek yolcuların gerekse de araçların yolları kullanmasıyla gerçekleşen ulaştırma eylemiyle birlikte ise, sefer hali denilen bir trafik oluşmaktadır.

Bir karayolundaki trafik; yolun hacmi, ilgili yoldaki araçların türleri ve nitelikleri gibi hususlar tarafından belirlenmektedir. Trafik mühendisliği ise; sürücü ile yolcular, araçlar ve yolun karakteristik özellikleri gibi 3 temel konudan ibarettir. Bir ulaşım sisteminin plan, tasarım ve uygulanmasinda bu 3 temel faktör ile bu faktörlerin birbirleriyle ilişkileri belirleyicidir. Meteorolojik olaylar ile gün ve saat de bu süreçte etkilidir (Yılmaz, 2006).

\subsection{Hiz}

Hiz, belirli bir zaman diliminde kat edilen yoldur (Kopal, 2011). Zaman ve mesafe bazlı olarak hız tanımlamaları yapılabilir (Turner, Eisele, Benz, \& Holdener, 1998):

Zaman- Ortalama Hızı: Birim zamanda, bir yolun sadece bir noktasından geçen taşıtların hızlarının ortalamasıdır. Yolun noktası baz alınarak ölçülür.

Mesafe- Ortalama Hızı: Birim zamanda, belli bir yol bölümünden geçen taşıtların hızlarının ortalamasıdır. Karayolunun uzunluğu baz alınarak ölçülür.

\subsection{Yoğunluk}

Belirli bir zaman diliminde, bir yoldan veya o yolun bir bölümünden geçen taşıt miktarına yoğunluk denir. Yoğunluk, taşıt/ km cinsinden ifade edilir. Yoldaki iki araç arasındaki mesafeyi de ifade etmesi bakımından bir karayolundaki yoğunluk, ilgili yoldaki hizmet seviyesinin belirlenmesi açısından önemli bir faktördür (Kopal, 2011).

\subsection{Hizmet Seviyeleri}

Bir yolun hizmet seviyesi; hız, yolculuk süresi, taşıtların manevra serbestisi ve duraksamaları gibi performans kriterleri baz alınarak değerlendirilir. Hizmet seviyeleri, sıkışıklığın az olmasından çok olmasına doğru A ile F arasında değişmektedir. Seviye bazlı tanımlamalar Tablo 1' de, hız bazlı Hizmet Seviyeleri ise Tablo 2' de gösterilmiştir (HCM, 2000):

Tablo 1. Hizmet seviyeleri

\begin{tabular}{cc}
\hline Seviye & Akış Durumu \\
\hline A & Serbest \\
\hline B & Makul Serbest \\
\hline C & Kararlı \\
\hline D & Kararsıza Yakın \\
\hline E & Kararsız \\
\hline F & Zorlama veya Kırılma \\
\hline
\end{tabular}

En az yoğunluk A düzeyi hizmet seviyelerinde görülürken sırasıyla $B, C, D, E$ ve $F$ düzeylerinde yoğunluk artmaktadır. F seviyesindeki dur- kalk koşullarını tahmin etmek zor olduğundan F seviyesi değerlendirme dışı bırakılmış ve 5 hizmet seviyesi üzerinden hız bazlı değerlendirme yapılmıştır.

Servis akış hızı, birim zamanda yolun bir noktası veya bir parçasından geçmesi beklenen araçların saatlik makul hız düzeyidir. Yol kullanıcıları için kabul edilebilir bir işletim hizmeti sağlamak amacıyla genellikle $\mathrm{C}$ veya $\mathrm{D}^{\prime}$ deki servis akış hızlarını kullanılmaktadır. Tabloda; ayrıca, çeşitli serbest akış hız düzeyleri için maksimum yoğunluk, ortalama hız, maksimum hacim ve kapasite oranı ve şerit bazlı saatlik araç sayısı verilmiştir. 
Tablo 2. Çok şeritli yollarda hizmet seviyeleri

\begin{tabular}{|c|c|c|c|c|c|c|}
\hline \multicolumn{7}{|c|}{ Hizmet Seviyeleri } \\
\hline Serbest & & & & & & \\
\hline Akış & & & & & & \\
\hline Hiz1 & Kriterler & A & B & $\mathrm{C}$ & $\mathrm{D}$ & $\mathrm{E}$ \\
\hline \multirow{4}{*}{100} & Maksimum yoğunluk (araç / km / şerit) & 7 & 11 & 16 & 22 & 25 \\
\hline & Ortalama hız (km / sa) & 100 & 100 & 98.4 & 91.5 & 88 \\
\hline & Maksimum hacim / kapasite oran $1 \mathrm{v} / \mathrm{c}$ ) & 0.32 & 0.50 & 0.72 & 0.92 & 1.00 \\
\hline & Maksimum servis akış hızı (araç / sa / şerit) & 700 & 1100 & 1575 & 2015 & 2200 \\
\hline \multirow{4}{*}{90} & Maksimum yoğunluk (araç / km / şerit) & 7 & 11 & 16 & 22 & 26 \\
\hline & Ortalama hiz $(\mathrm{km} / \mathrm{sa})$ & 90 & 90 & 89.8 & 84.7 & 80.8 \\
\hline & Maksimum hacim / kapasite oran1 (v / c) & 0.30 & 0.47 & 0.68 & 0.89 & 1.00 \\
\hline & Maksimum servis akıs hızı (arac / sa / serit) & 630 & 990 & 1435 & 1860 & 2100 \\
\hline \multirow{4}{*}{80} & Maksimum yoğunluk (araç / km / şerit) & 7 & 11 & 16 & 22 & 27 \\
\hline & Ortalama hiz $(\mathrm{km} / \mathrm{sa})$ & 80 & 80 & 80 & 77.6 & 74.1 \\
\hline & Maksimum hacim / kapasite oran1 (v / c) & 0.28 & 0.44 & 0.64 & 0.85 & 1.00 \\
\hline & Maksimum servis akıș hızı (araç / sa / şerit) & 560 & 880 & 1280 & 1705 & 2000 \\
\hline \multirow{4}{*}{70} & Maksimum yoğunluk (araç / km / şerit) & 7 & 11 & 16 & 22 & 28 \\
\hline & Ortalama hız (km / sa) & 70 & 70 & 70 & 69.6 & 67.9 \\
\hline & Maksimum hacim / kapasite oran 1 (v / c) & 0.26 & 0.41 & 0.59 & 0.81 & 1.00 \\
\hline & Maksimum servis akıș hızı (araç / sa / șerit) & 490 & 770 & 1120 & 1530 & 1900 \\
\hline
\end{tabular}

\section{3. İstanbul'da Ulaşım}

Tablo 3' te, 2010- 2018 arası dönem için toplam nüfus, motorlu kara taşıt sayısı ve otomobil sayısı, bin kişi başına otomobil sayısı, trafik kazası ve akabinde yaşanan ölüm sayısı gösterilmiştir. İlgili yıllarda, nüfus ve araç sayılarındaki sürekli artışa rağmen, bin kişi başına düşen otomobil sayısındaki oranının da devamlı yükselmesi, İstanbul' daki artan trafik yoğunluğunu göstermesi açısından önemlidir. Bu yoğunluk artışıyla birlikte, meydana gelen trafik kazaları ve neticesindeki ölüm sayıları da yükselmektedir (TÜiK, 2020).

Tablo 3. İstanbul' da ulaşım ile ilgili çeşitli bilgiler

\begin{tabular}{|c|c|c|c|c|c|c|}
\hline Y1l & $\begin{array}{c}\text { Toplam } \\
\text { Nüfus }\end{array}$ & $\begin{array}{c}\text { Otomobil } \\
\text { Sayıs1 }\end{array}$ & $\begin{array}{l}\text { Motorlu } \\
\text { Kara } \\
\text { Taşıtları } \\
\text { Sayısı } \\
\end{array}$ & $\begin{array}{l}\text { Bin Kişi } \\
\text { Başına } \\
\text { Otomobil } \\
\text { Say1s1 }\end{array}$ & $\begin{array}{c}\text { Trafik } \\
\text { Kaza } \\
\text { Sayıs1 }\end{array}$ & $\begin{array}{l}\text { Ölüm } \\
\text { Sayıs1 }\end{array}$ \\
\hline 2010 & 11121331 & 1821694 & 2794236 & 137 & 11934 & 52812 \\
\hline 2011 & 12834113 & 1907782 & 2927650 & 140 & 13887 & 53165 \\
\hline 2012 & 14688296 & 2009777 & 3006465 & 145 & 15082 & 54696 \\
\hline 2013 & 16307943 & 2146257 & 3230908 & 152 & 15224 & 54770 \\
\hline 2014 & 17855440 & 2274368 & 3383812 & 158 & 15577 & 58009 \\
\hline 2015 & 19145632 & 2463995 & 3624403 & 168 & 16081 & 60093 \\
\hline 2016 & 16238391 & 2644411 & 3845349 & 179 & 16102 & 62563 \\
\hline 2017 & 17837519 & 2813027 & 4061725 & 187 & 15497 & 63371 \\
\hline 2018 & 20892537 & 2887581 & 4173312 & 192 & 16601 & 62503 \\
\hline
\end{tabular}

\section{Meteorolojik Değişkenler}

\subsection{Isı ve Sicaklık}

Cisimlerde var olan kuvvete 1sı, bu kuvvetin kinetik olarak ortaya çıkmasına ise sıcaklık denir (Eken vd., 2008). Meteorolojik olayların yaşanmasında sıcaklık önemli bir rol oynamaktadır. Farklı sıcaklıklara sahip ortamlarda meydana gelen 1sı değişimleri; radyasyon, konveksiyon ve kondüksiyon ile oluşur (Aküzüm vd., 1994). 


\subsection{Rüzgar}

Akıcı özelliğe haiz olan havanın yatay olarak yer değiştirmesi rüzgar olarak adlandırılır (Eken vd., 2008). Sıcaklık artışıyla birlikte hava genişleyip yükselir ve alçak basınç alanı oluşur. Bu alana komşu ve sıcaklığın kısmen daha az olduğu alanda ise soğuk olan hava sıkışıp alçalır ve yüksek basınç alanı oluşur. Yüksek basınç alanından, oluşan bu alçak basınç alanına doğru olan hava akışıyla rüzgar olayı meydana gelir (Aküzüm vd., 1994).

\subsection{Bulut}

Bulut; buz, su veyahut bunların çekirdeklerinin gözle görülebilen bileşimidir (Gültekin, Demircan, Ulupınar, \& Bulut, 2005). Atmosferde su buharı olarak yer alan havanın, alçak basınç seviyelerinde soğuması ve buz kristali veya küçük su damlaları haline gelmesiyle bulut meydana gelir.

\subsection{Sis}

Yüzeye yakın kısımlardaki nemin soğuması ve yoğunlaşması ile sis denilen havada asılı haldeki su damlacıkları oluşur (MGM, 2020). Yüzeye yakın yerdeki soğuma ile havadaki nem miktarındaki artma, sisin oluşması için gerekli etkenlerdir (Eken vd., 2008).

\subsection{Nem}

Havada bulunan su buharına nem denir ve nem, genellikle yeryüzüne yakın yerlerde bulunur. Atmosfere gerekli olan nem ise hidrosfer tarafindan sağlanmaktadır (Aküzüm vd., 1994).

\subsection{Yağmur}

Yeryüzüne düşen su damlalarına yağmur denir. Çapları $0.5 \mathrm{~mm}$ ' den büyüktür ve damlanın boyutu arttıkça yeryüzüne düşme hızı da artmaktadır (Aküzüm vd., 1994).

\section{Yapay Sinir Ağları}

Walter Pits ve Warren McCulloch' un1943 y1lında ürettiği ilk yapay nöronun akabinde 1970’ li yıllarda önemli gelişmeler yaşanmış olan Yapay Sinir Ağları, bu günden itibaren günlük hayatta daha fazla kullanılmaya başlanmıştır.

Yapay Sinir Ağları (YSA); girdi katmanı, ara katman ve çıktı katmanı olmak üzere birbirine paralel 3 katmandan meydana gelmektedir. YSA, dışarıdaki bilginin ağlar vasıtasıyla elde edilmesi ve 'öğrenme algoritması' denilen algoritma ile öğrenme işlemi gerçekleşene kadar periyodik döngüler halinde ağırlıklarının değiştirilmesi açılarından insan beynine benzer (Haykin, 1998). Sinir Ağları, hücrelere dışarıdan farklı ağırlıklandırmalar ile gelen verilerin, bir toplama fonksiyonunda toplanması ve akabinde aktivasyon fonksiyonundan geçirilip diğer hücrelere aktarılmasından ibarettir (Maind \& Wankar, 2014; Öztemel, 2016; Öztürk \& Şahin, 2018).

\section{Araştırmanın Amaç ve Yöntemi}

$\mathrm{Bu}$ araştırmada, araç geçiş sayısının fazla olduğu bir karayolunda hız tahmini yapılarak, bu tahmin üzerinden ilgili yolda yaşanabilecek olası trafik yoğunluğunun tespit edilmesi amaçlanmıştır. Bağımlı değişken hız iken; bağımsız değişken olarak; sıcaklık, nem ve rüzgar hızı, hafta içi günler, gözlem yapılan mesai saatleri ve hava koşulu değişkenleri kullanılmıştır. Gün, saat ve hava koşulu kategorik değişkenleri; dummy değişken (kukla değişken) olarak belirlenmiş ve böylece toplamda 28 bağımsız değişken elde edilmiştir. Model 2 tane gizli katmanlı olarak düşünülmüştür. Böylece modelde, bağımsız değişkenlerden oluşan 28 girdi katmanı, 25' li olmak üzere 2 tane gizli katman, 1 tane de çıtı katmanı mevcuttur. Tasarlanan model Şekil 1'de gösterilmiş̧ir. Ayrıca değişkenlere ait istatistiki bilgiler Tablo 4' te gösterilmiştir. 
Tablo 4. Değişkenler dair istatistiki bilgiler

\begin{tabular}{ccccc}
\hline & Hiz $(\mathrm{km})$ & Sicaklık $(\mathrm{C})$ & Nem & Rüzgar Hizı \\
\hline $\mathrm{N}$ & 1760 & 1760 & 1760 & 1760 \\
\hline Minimum & 65 & 2 & 10 & 0 \\
\hline Maximum & 95 & 32 & 94 & 50 \\
\hline Mean & 81.40 & 22,09 & 62.74 & 16.570 \\
\hline Std. Deviation & 7.571 & 5.694 & 16.570 & 9.802 \\
\hline Variance & 57.318 & 32.426 & 274.553 & 96.088 \\
\hline
\end{tabular}

Bă̆ımsız Değişkenler: Sıcaklık (C); Nem; Rüzgar Hızı; Hava Durumu (Yağmurlu, Bulutlu, Sisli, Açık); Hafta içi Gün (Pazartesi, Sall, Çarşamba, Perşembe, Cuma); Mesai Saatleri (8:20 ÖÖ, 8:50 ÖÖ, 9:20 ÖÖ, 9:50 ÖÖ, 10:20 ÖÖ, 10:50 ÖÖ, 11:20 ÖÖ, 11:50 ÖÖ, 1:20 ÖS, 1:50 ÖS, 2:20 ÖS, 2:50 ÖS, 3:20 ÖS, 3:50 ÖS, 4:20 ÖS, 4:50 ÖS)

\section{Bă̆ımlı Değişken: Hız}

Bağımlı değişken olan hız verisi; $65-95$ km saat arasında olup ortalama 81.40 km' dir. Bağımsız değişkenlerden sıcaklık, 2- 32 C arasında ve ortalama 22.09 C; Nem 10- 94 aralığında ve ortalama 62.74; rüzgar hızı ise, 0 - 50 aralığında ve ortalama 16.570 ' dir.

Şekil 1. Yapay sinir ağı modeli

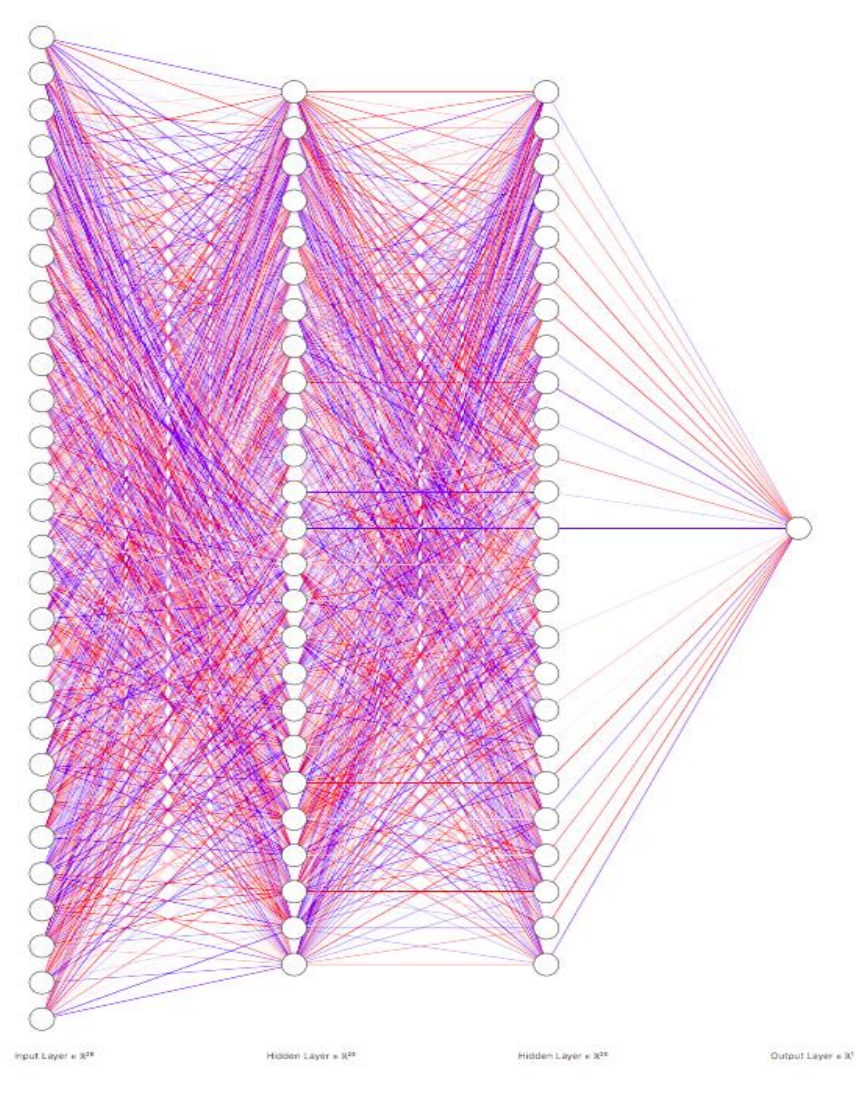

\section{Araştırma Bulguları}

Değişkenlere ait korelasyon değerlerinin gösterildiği Tablo 5' te görüldüğü üzere; hız bağımlı değişkeni ve, rüzgar hızı (-.645) bağımsız değişkeni arasında 0.05 anlamlılık düzeyinde, sicaklık (.-714) bağımsız değişkeni ile de 0.01 anlamlılık düzeyinde yüksek bir korelasyon varken, nem (.308), saat (.307) ve hava durumu (.205) bağımsız değişkenleri ile de yine 0.01 
düzeyinde fakat zayıf bir düzeyde korelasyon vardır. Gün (-.069) bağımsız değişkenleri ile hız bağımlı değişkeni arasında ise 0.01 anlamlılık düzeyinde çok zayıf bir korelasyon vardır.

Tablo 5. Korelasyon matrisi

\begin{tabular}{|c|c|c|c|c|c|c|c|c|}
\hline & & $\mathrm{H} 1 \mathrm{z}$ & $\begin{array}{c}\text { Hava } \\
\text { Durumu }\end{array}$ & Gün & Zaman & Sicaklık & $\mathrm{Nem}$ & $\begin{array}{c}\text { Rüzgar } \\
\text { Hızl }\end{array}$ \\
\hline \multirow[t]{3}{*}{$\mathrm{H} 1 \mathrm{z}$} & $\begin{array}{c}\text { Pearson } \\
\text { Correlation } \\
\end{array}$ & 1 & & & & & & \\
\hline & $\begin{array}{l}\begin{array}{l}\text { Sig. (2- } \\
\text { tailed) }\end{array} \\
\end{array}$ & & & & & & & \\
\hline & $\mathrm{N}$ & 1760 & & & & & & \\
\hline \multirow[t]{3}{*}{$\begin{array}{c}\text { Hava } \\
\text { Durumu }\end{array}$} & $\begin{array}{c}\text { Pearson } \\
\text { Correlation } \\
\end{array}$ & $.205 * *$ & 1 & & & & & \\
\hline & $\begin{array}{l}\begin{array}{l}\text { Sig. (2- } \\
\text { tailed) }\end{array} \\
\end{array}$ & .000 & & & & & & \\
\hline & $\mathrm{N}$ & 1760 & 1760 & & & & & \\
\hline \multirow[t]{3}{*}{ Gün } & $\begin{array}{c}\text { Pearson } \\
\text { Correlation }\end{array}$ & $-.069 * *$ & -.008 & 1 & & & & \\
\hline & $\begin{array}{l}\text { Sig. (2- } \\
\text { tailed) }\end{array}$ & .004 & .746 & & & & & \\
\hline & $\mathrm{N}$ & 1760 & 1760 & 1760 & & & & \\
\hline \multirow[t]{3}{*}{ Saat } & $\begin{array}{c}\text { Pearson } \\
\text { Correlation }\end{array}$ & $-.307 * *$ & -.022 & .000 & 1 & & & \\
\hline & $\begin{array}{l}\text { Sig. (2- } \\
\text { tailed) }\end{array}$ & .000 & .354 & 1.000 & & & & \\
\hline & $\mathrm{N}$ & 1760 & 1760 & 1760 & 1760 & & & \\
\hline \multirow[t]{3}{*}{ Sicaklık } & $\begin{array}{c}\text { Pearson } \\
\text { Correlation }\end{array}$ & $-.714 * *$ & $-.246^{* *}$ & .026 & $.287 * *$ & 1 & & \\
\hline & $\begin{array}{l}\text { Sig. (2- } \\
\text { tailed) }\end{array}$ & .000 & .000 & .271 & .000 & & & \\
\hline & $\mathrm{N}$ & 1760 & 1760 & 1760 & 1760 & 1760 & & \\
\hline \multirow[t]{3}{*}{$\mathrm{Nem}$} & $\begin{array}{c}\text { Pearson } \\
\text { Correlation } \\
\end{array}$ & $.308 * *$ & $.123 * *$ & $.127 * *$ & $-.437 * *$ & $-.568 * *$ & 1 & \\
\hline & $\begin{array}{l}\begin{array}{l}\text { Sig. (2- } \\
\text { tailed) }\end{array} \\
\end{array}$ & .000 & .000 & .000 & .000 & .000 & & \\
\hline & $\mathrm{N}$ & 1760 & 1760 & 1760 & 1760 & 1760 & 1760 & \\
\hline \multirow[t]{3}{*}{$\begin{array}{c}\text { Rüzgar } \\
\text { Hiz1 }\end{array}$} & $\begin{array}{c}\text { Pearson } \\
\text { Correlation }\end{array}$ & $-.645^{* * *}$ & $-.085^{* *}$ & $.055^{*}$ & $.355^{* *}$ & $.447 * *$ & $-.188^{* *}$ & 1 \\
\hline & $\begin{array}{l}\text { Sig. (2- } \\
\text { tailed) }\end{array}$ & .000 & .000 & .021 & .000 & .000 & .000 & \\
\hline & $\mathrm{N}$ & 1760 & 1760 & 1760 & 1760 & 1760 & 1760 & 1760 \\
\hline
\end{tabular}

Regresyon analizi, Sıradan En Küçük Kareler Yöntemi olan OLS (Ordinary Least Squared) ile yapılmıştır. R-Squared (R2) değerinin 0.85 olduğu görülmüş ve genel kabul değeri olan 0.70 ' in üzerinde ve iyi bir sonuç olduğu görülmüştür. Adjusted (Düzeltilmiş) R-Squared değeri ise 0.853 olup R2 değerine yakın ve iyi bir sonuçtur. P değeri ise .05 'den küçüktür ve bağımsız değiş̧kenlerin katsayılarının istatistiksel olarak anlamlı olduğu görülmektedir. Tablo 6' daki Coefficients (Katsayılar), regresyon katsayısını gösterir ve her bir değişkenin değeri, o değişkende bir birimlik değişim olursa, tahmin edilen hızın ne kadar değişeceğini gösterir. 
Tablo 6. Regresyon katsayıları

\begin{tabular}{cccc}
\hline Bağımsız Değişken & Coefficients & Bağımsız Değişken & Coefficients \\
\hline Sıcaklık & -0.8199 & Saat - 11:20:00 & 158.690 \\
\hline Nem & 0.0579 & Saat - 11:50:00 & 114.890 \\
\hline Rüzgar Hızı & -0.2441 & Saat - 13:20:00 & 107.070 \\
\hline Gün- Pazartesi & 383.573 & Saat - 13:50:00 & 159.488 \\
\hline Gün- Sal1 & 389.553 & Saat - 14:20:00 & 159.029 \\
\hline Gün- Çarşamba & 390.235 & Saat - 14:50:00 & 160.138 \\
\hline Gün- Perşembe & 383.877 & Saat - 15:20:00 & 112.492 \\
\hline Gün- Cuma & 388.293 & Saat - 15:50:00 & 111.028 \\
\hline Saat - 08:20:00 & 81.643 & Saat - 16:20:00 & 111.165 \\
\hline Saat - 08:50:00 & 79.881 & Saat - 16:50:00 & 62.061 \\
\hline Saat - 09:20:00 & 121.480 & Hava Koşulu - Bulutlu & 476.154 \\
\hline Saat - 09:50:00 & 119.326 & Hava Koşulu - Güneşli & 521.600 \\
\hline Saat -_10:20:00 & 117.062 & Hava Koşulu - Sisli & 491.442 \\
\hline Saat - 10:50:00 & 160.089 & Hava Koşulu - Yağmurlu & 446.336 \\
\hline & & &
\end{tabular}

Çalışmadaki verilerin \% 80' ni öğrenme verisi, \% 20’ si ise test verisi olarak ayrılmıştır. Kök Ortalama Kare Mantıksal Hatası (RMSLE), gerçek ve tahmini değer arasındaki oranı; Kök Ortalama Kare Hatası (RMSE) ise, modelin performansını ölçmektedir ve bu değerlerin sıfıra yakınlığı, modelin ne kadar iyi sonuç verdiğini göstermektedir (Janik vd, 2018). Modele ait RMSE değeri 3.34, RMSLE değeri ise 0.04' tür.

\subsection{Mesai Saatleri Bazlı Hız Tahmini}

Bağımsız değişkenler arasından sıcaklık, nem ve rüzgar hızı değerleri görülme sıklığı üzerinden, gün olarak pazartesi günü ve hava durumu olarak da bulutlu seçeneği sabit varsayımlar olarak alınmıştır.

Tablo 7' de görüldüğü üzere, en yüksek hız tahmini; 2:20 ÖS saatinde 82.09 ile, en düşük hız tahminin ise 4:50 ÖS' de 71.76 ile yapılmıştır. Tahminlerden hareketle; 9:20 ÖÖ, 10:20 ÖÖ, 10:50 ÖÖ, 11:20 ÖÖ, 1:50 ÖS ve 2:20 ÖS saatlerinde hız tahminlerinin kendinden bir önceki saate göre artış gösterdiği, diğer saatlerde ise bir önceki ölçüme kıyasla azalma meydana geldiği görülmektedir.

Tablo 7. Mesai saatleri bazlı hız tahmini

\begin{tabular}{|c|c|c|c|c|c|c|c|c|c|}
\hline \multicolumn{2}{|c|}{ Varsayımlar } & Saat & $\begin{array}{c}\text { Hiz } \\
\text { Tahmini }\end{array}$ & Saat & $\begin{array}{c}\text { Hiz } \\
\text { Tahmini }\end{array}$ & Saat & $\begin{array}{c}\text { Hiz } \\
\text { Tahmini }\end{array}$ & Saat & $\begin{array}{c}\mathrm{H} 1 \mathrm{z} \\
\text { Tahmini }\end{array}$ \\
\hline Sicaklık & 23 & $\begin{array}{l}8: 20 \\
\text { ÖÖ }\end{array}$ & 73.39 & $\begin{array}{c}\text { 10:50 } \\
\text { ÖÖ }\end{array}$ & 81.59 & $\begin{array}{c}2: 20 \\
\text { ÖS }\end{array}$ & 82.09 & $\begin{array}{c}4: 50 \\
\text { ÖS }\end{array}$ & 71.76 \\
\hline $\mathrm{Nem}$ & 63 & $\begin{array}{l}8: 50 \\
\text { ÖÖ }\end{array}$ & 72.84 & $\begin{array}{c}11: 20 \\
\text { ÖÖ }\end{array}$ & 81.84 & $\begin{array}{c}2: 50 \\
\text { ÖS }\end{array}$ & 81.70 & & \\
\hline $\begin{array}{c}\text { Rüzgar } \\
\text { Hızı }\end{array}$ & 21 & $\begin{array}{c}9: 20 \\
\text { ÖÖ }\end{array}$ & 77.32 & $\begin{array}{c}11: 50 \\
\text { ÖÖ }\end{array}$ & 76.85 & $\begin{array}{c}3: 20 \\
\text { ÖS }\end{array}$ & 76.92 & & \\
\hline Gün & Pazartesi & $\begin{array}{l}\text { 9:50 } \\
\text { ÖÖ }\end{array}$ & 77.10 & $\begin{array}{l}1: 20 \\
\text { ÖS }\end{array}$ & 76.26 & $\begin{array}{c}3: 50 \\
\text { ÖS }\end{array}$ & 76.68 & & \\
\hline $\begin{array}{l}\text { Hava } \\
\text { Durumu }\end{array}$ & Bulutlu & $\begin{array}{c}10: 20 \\
\text { ÖÖ }\end{array}$ & 77.81 & $\begin{array}{l}1: 50 \\
\text { ÖS }\end{array}$ & 82.07 & $\begin{array}{c}4: 20 \\
\text { ÖS }\end{array}$ & 76.33 & & \\
\hline
\end{tabular}




\subsection{Haftaiçi Gün Bazlı Hız Tahmini}

Tablo 8' de bağımsız değişkenler arasından sıcaklık, nem ve rüzgar hızı değerleri görülme sıklığı üzerinden, mesai saati olarak 08:20' de yapılan ölçüm ve hava durumu olarak da bulutlu seçeneği sabit varsayımlar olarak alınmıştır.

Tablo 8. Hafta içi gün bazlı hız tahmini

\begin{tabular}{cc|cc}
\hline Varsayımlar & & Gün & Hız Tahmini \\
\hline Sicaklık & 23 & Pazartesi & 73.39 \\
Nem & 63 & Salı & 73.92 \\
Rüzgar Hızı & 21 & Çarşamba & 73.15 \\
Saat & $08: 20$ & Perşembe & 73.57 \\
Hava Durumu & Bulutlu & Cuma & 73.68 \\
\hline
\end{tabular}

En yüksek hız tahmininin; Salı günü 73.92 ile, en düşük hız tahmininin ise Çarşamba günü 73.15 ile yapıldığı görülmektedir. Tahminlerden hareketle; Salı, Perşembe ve Cuma günlerinde elde edilen hız tahminlerinin kendinden bir önceki güne göre artış gösterdiği, diğer günlerde ise bir önceki ölçüme kıyasla azalma meydana geldiği görülmektedir.

\subsection{Sıcaklık Bazlı Hız Tahmini}

Tablo 9' da görüldüğü üzere; bağımsız değişkenler arasından nem ve rüzgar hızı değerleri görülme sıklı̆̆g üzerinden, gün olarak pazartesi günü, mesai saati olarak 08:20' de yapılan ölçüm ve hava durumu olarak da bulutlu seçeneği sabit varsayımlar olarak alınmıştır.

En yüksek hız tahminin ölçümü yapılan değerlerden en düşük değer olan 2 sıcaklık değeri için 86.92 ile, en düşük hız tahminin ise 29 sıcaklık değeri için 68.01 ile yapıldığ 1 görülmektedir. Tahminlerden hareketle; en düşük olan 2 değerinden 29 sıcaklık değerine kadar elde edilen hız tahminlerinin kendinden bir önceki güne göre sürekli azalış gösterdiği, sonraki ölçüm olan 32 sıcaklık değerinde ise bir önceki ölçüme kıyasla artış meydana geldiği görülmektedir.

Tablo 9. Sicaklik bazlı hiz tahmini

\begin{tabular}{cc|cc|cc|cc}
\hline \multicolumn{2}{c|}{ Varsayımlar } & Sicaklık & $\begin{array}{c}\text { Hız } \\
\text { Tahmini }\end{array}$ & Sicaklık & $\begin{array}{c}\text { Hiz } \\
\text { Tahmini }\end{array}$ & Sicaklık & $\begin{array}{c}\text { Hız } \\
\text { Tahmini }\end{array}$ \\
\hline Nem & 63 & 2 & 86.92 & 17 & 78.78 & 32 & 68.29 \\
Rüzgar Hızı & 21 & 5 & 86.79 & 20 & 76.08 & & \\
Gün & Pazartesi & 8 & 86.65 & 23 & 73.39 & & \\
Saat & $08: 20$ & 11 & 84.16 & 26 & 70.70 & & \\
Hava & Bulutlu & 14 & 81.47 & 29 & 68.01 & & \\
Durumu & & & & & & & \\
\hline
\end{tabular}

\subsection{Nem Bazlı Hız Tahmini}

Bağımsız değişkenler arasından sıcaklık ve rüzgar hızı değerleri görülme sıklığı üzerinden, gün olarak pazartesi günü, mesai saati olarak 08:20' de yapılan ölçüm ve hava durumu olarak da bulutlu seçeneği sabit varsayımlar olarak alınmıştır.

Tablo 10' dan hareketle; en yüksek hız tahminin 10 nem seviyesinde 83.29 ile, en düşük hız tahminin ise 40 nem seviyesinde 70.69 ile yapıldığı görülmektedir. Tahminlerden hareketle; 10 nem seviyesinden 40 nem seviyesi dahil elde edilen hiz tahminlerinin kendinden bir önceki güne göre azalış gösterdiği ve en düşük hız seviyesine 40 nem seviyesinde ulaştığ 1 , 50 nem seviyesinden başlayıp son ölçüm seviyesi olan 100 nem seviyesi de dahil olmak üzere bir önceki ölçüme kıyasla artış meydana geldiği görülmektedir. 
Tablo 10. Nem bazlı hiz tahmini

\begin{tabular}{cc|cc|cc}
\hline \multicolumn{2}{c|}{ Varsayımlar } & Nem & Hiz Tahmini & Nem & Hiz Tahmini \\
\hline Sicaklık & 23 & 10 & 83.29 & 60 & 73.02 \\
Rüzgar Hızı & 21 & 20 & 76.30 & 70 & 74.26 \\
Gün & Pazartesi & 30 & 72.64 & 80 & 75.49 \\
Saat & $08: 20$ & 40 & 70.69 & 90 & 77.03 \\
Hava Durumu & Bulutlu & 50 & 71.78 & 100 & 79.06 \\
\hline
\end{tabular}

\subsection{Rüzgar Hızı Bazlı Hız Tahmini}

Bağımsız değişkenler arasından sıcaklık ve nem değerleri görülme sıklığı üzerinden, gün olarak pazartesi günü, mesai saati olarak 08:20' de yapılan ölçüm ve hava durumu olarak da bulutlu seçeneği sabit varsayımlar olarak alınmıştır.

Tablo 11. Rüzgar hızı bazlı hız tahmini

\begin{tabular}{cccccccc}
\hline \multicolumn{2}{c}{ Varsayımlar } & $\begin{array}{c}\text { Rüzgar } \\
\text { Hızı }\end{array}$ & $\begin{array}{c}\text { Hız } \\
\text { Tahmini }\end{array}$ & $\begin{array}{c}\text { Rüzgar } \\
\text { Hız1 }\end{array}$ & $\begin{array}{c}\text { Hız } \\
\text { Tahmini }\end{array}$ & $\begin{array}{c}\text { Rüzgar } \\
\text { Hız1 }\end{array}$ & $\begin{array}{c}\text { Hız } \\
\text { Tahmini }\end{array}$ \\
\hline Sicaklık & 23 & 0 & 78.50 & 25 & 72.91 & 50 & 79.04 \\
Nem & 63 & 5 & 77.86 & 30 & 72.36 & & \\
Gün & Pazartesi & 10 & 76.20 & 35 & 72.21 & & \\
Saat & $08: 20$ & 15 & 74.12 & 40 & 74.22 & & \\
Hava & Bulutlu & 20 & 73.51 & 45 & 76.63 & & \\
Durumu & & & & & & & \\
\hline
\end{tabular}

Tablo 11' de görüldüğü üzere; en yüksek hız tahminin 50 rüzgar hızı seviyesinde 79.04 ile, en düşük hız tahminin ise 35 rüzgar hızı seviyesinde 72.21 ile yapıldığı görülmektedir. Tahminlerden hareketle; 0 rüzgar hızı seviyesinden 35 rüzgar hızı seviyesi dahil elde edilen hız tahminlerinin kendinden bir önceki güne göre azalış gösterdiği ve en düşük hız seviyesine 35 rüzgar hızı seviyesinde ulaştığı, 40 rüzgar hızı seviyesinden başlayıp son ölçüm seviyesi olan 50 rüzgar hızı seviyesi de dahil olmak üzere bir önceki ölçüme kıyasla artış meydana geldiği ve en yüksek hız tahminine 50 rüzgar hızı seviyesinde ulaştığı görülmektedir.

\subsection{Hava Durumu Bazlı Hız Tahmini}

Tablo 12' de de görüldüğg̈ gibi; bağımsız değişkenler arasından sıcaklık, nem ve rüzgar hızı değerleri görülme sıklığ de yapılan ölçüm sabit varsayımlar olarak alınmıştır. En yüksek hız tahminin Açık hava koşullarında 78.37 ile, en düşük hız tahminin ise Yağmurlu hava koşullarında 68.83 ile yapıldığ görülmektedir. Tahminlerden hareketle; Açık hava koşullarında elde edilen hız tahminlerinin kendinden bir önceki güne göre artış gösterdiği, diğer günlerde ise bir önceki ölçüme kıyasla azalma meydana geldiği görülmektedir.

Tablo 12. Hava durumu bazlı hız tahmini

\begin{tabular}{|cc|cc|}
\hline \multicolumn{2}{|c|}{ Varsayımlar } & Hava Durumu & Hız Tahmini \\
\hline Sıcaklık & 23 & Bulutlu & 73.39 \\
Nem & 63 & Açık & 78.37 \\
Rüzgar Hızı & 21 & Sisli & 72.64 \\
Gün & Pazartesi & Yağmurlu & 68.83 \\
Saat & $08: 20$ & & \\
\hline
\end{tabular}


Tablo 13. İlk gün değişkenleri, gerçek ve tahmini hız değeri ile aralarındaki fark

\begin{tabular}{|c|c|c|c|c|c|c|c|c|}
\hline Gün & Saat & Sicaklık & $\mathrm{Nem}$ & $\begin{array}{c}\text { Rüzgar } \\
\text { H1zı }\end{array}$ & $\begin{array}{c}\text { Hava } \\
\text { Koşulu }\end{array}$ & $\begin{array}{c}\text { H1z } \\
\text { (Gerçek } \\
\text { Değer) }\end{array}$ & $\begin{array}{c}\mathrm{H} 1 \mathrm{z} \\
\text { (Tahmin } \\
\text { Değeri) }\end{array}$ & Fark \\
\hline $\begin{array}{c}\text { 2019-07- } \\
10\end{array}$ & $8: 20$ ÖÖ & 24 & 83 & 20 & Bulutlu & 75 & 75,29 & $\begin{array}{c}- \\
0,29\end{array}$ \\
\hline $\begin{array}{c}\text { 2019-07- } \\
10\end{array}$ & 8:50 ÖÖ & 24 & 83 & 17 & Bulutlu & 75 & 75,83 & $\begin{array}{c}- \\
0,83\end{array}$ \\
\hline $\begin{array}{c}\text { 2019-07- } \\
10\end{array}$ & 9:20 ÖÖ & 25 & 74 & 17 & Bulutlu & 75 & 78,05 & $\begin{array}{c}- \\
3,05\end{array}$ \\
\hline $\begin{array}{c}\text { 2019-07- } \\
10\end{array}$ & 9:50 ÖÖ & 26 & 74 & 20 & Bulutlu & 70 & 75,98 & $\begin{array}{c}- \\
5,98\end{array}$ \\
\hline $\begin{array}{c}2019-07- \\
10\end{array}$ & $\begin{array}{c}\text { 10:20 } \\
\text { ÖÖ }\end{array}$ & 24 & 78 & 22 & Bulutlu & 80 & 78,40 & 1,60 \\
\hline $\begin{array}{c}2019-07- \\
10\end{array}$ & $\begin{array}{c}\text { 10:50 } \\
\text { ÖÖ }\end{array}$ & 25 & 74 & 22 & Bulutlu & 80 & 80,79 & $\begin{array}{c}- \\
0,79\end{array}$ \\
\hline $\begin{array}{c}\text { 2019-07- } \\
10\end{array}$ & $\begin{array}{c}11: 20 \\
\text { ÖÖ }\end{array}$ & 27 & 65 & 24 & Bulutlu & 75 & 77,89 & $\begin{array}{c}- \\
2,89\end{array}$ \\
\hline $\begin{array}{c}\text { 2019-07- } \\
10\end{array}$ & $\begin{array}{c}\text { 11:50 } \\
\text { ÖÖ }\end{array}$ & 26 & 65 & 28 & Bulutlu & 70 & 73,32 & $\begin{array}{c}- \\
3,32\end{array}$ \\
\hline $\begin{array}{c}\text { 2019-07- } \\
10\end{array}$ & $1: 20$ ÖS & 26 & 65 & 24 & Bulutlu & 70 & 73,21 & $\begin{array}{c}- \\
3,21\end{array}$ \\
\hline $\begin{array}{c}\text { 2019-07- } \\
10\end{array}$ & $2: 20$ ÖS & 27 & 65 & 22 & Bulutlu & 75 & 78,39 & $\begin{array}{c}- \\
3,39\end{array}$ \\
\hline $\begin{array}{c}\text { 2019-07- } \\
10\end{array}$ & $3: 20$ ÖS & 28 & 54 & 28 & Bulutlu & 70 & 70,23 & $\begin{array}{c}- \\
0,23\end{array}$ \\
\hline $\begin{array}{c}\text { 2019-07- } \\
10\end{array}$ & $4: 20$ ÖS & 26 & 57 & 31 & Bulutlu & 70 & 71,73 & $\begin{array}{c}- \\
1,73\end{array}$ \\
\hline $\begin{array}{c}\text { 2019-07- } \\
10\end{array}$ & $4: 50$ ÖS & 24 & 69 & 33 & Bulutlu & 70 & 69,91 & 0,09 \\
\hline $\begin{array}{c}\text { 2019-07- } \\
10\end{array}$ & $1: 50$ ÖS & 27 & 65 & 24 & Bulutlu & 75 & 78,12 & $\begin{array}{c}- \\
3,12\end{array}$ \\
\hline $\begin{array}{c}\text { 2019-07- } \\
10\end{array}$ & $2: 50$ ÖS & 27 & 61 & 26 & Bulutlu & 75 & 77,01 & $\begin{array}{c}- \\
2,01\end{array}$ \\
\hline $\begin{array}{c}\text { 2019-07- } \\
10\end{array}$ & $3: 50$ ÖS & 26 & 61 & 30 & Bulutlu & 70 & 72,41 & $\begin{array}{c}- \\
2,41\end{array}$ \\
\hline
\end{tabular}

Tablo 13 ve Şekil 2' de, değişkenlerin ilk gün ölçüm değerleri, bu değerler baz alınarak yapılan hız tahmini değeri ve gerçek ile tahmini hız değeri arasındaki fark değeri gösterilmiştir. İlk günkü 16 gözlem değeriyle yapılan tahmin sonucunda, tahmini hız değerlerinden 10 tanesinin 75- 80 aralığında olduğu görülmüştür. 
Şekil 2. Değişken bazlı hız tahminleri ve fark değeri

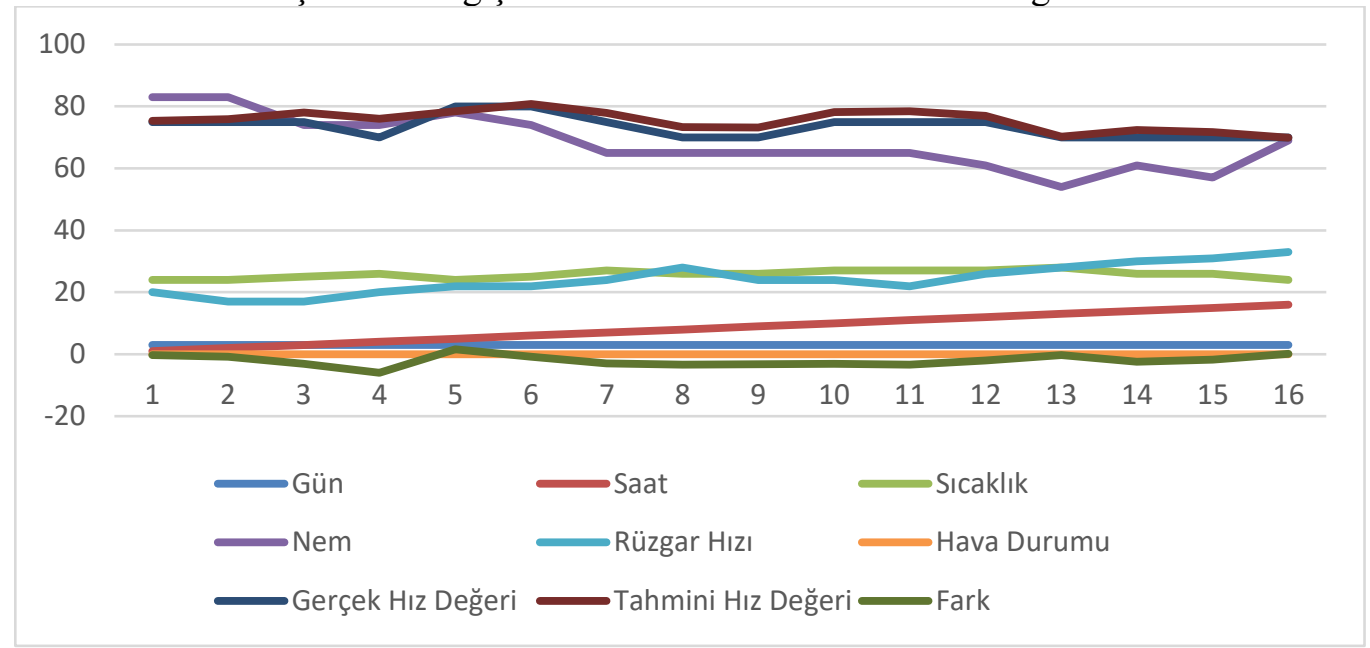

\section{Sonuç ve Değerlendirme}

Trafikte, hava koşullarının etkisini minimum düzeyde tutmak için bu koşulların etkisi ölçülmelidir (Maze vd. 2006). Bu çalışmada da, taşıt yoğunluğunun fazla olduğu bir yolda; meteorolojik değişkenler (nem, rüzgar hızı, sıcaklık ve hava koşulu) ile h.içi günler ve ilgili günlerdeki çalışma saatlerinin araçların hızıyla ve dolayısıyla trafik yoğunluğuyla ilişkisi incelenmiştir.

Soğuk hava ve kar yağışının trafik hacmi üzerindeki etkisi; gün, günün saati ve yolun türüne göre değişmektedir. Ayrıca, kar yağgşı trafik hacminde azalma meydana getirmektedir (Datla \& Sharma, 2008). Yol, görüş mesafesi ve rüzgâr şiddeti araçların serbest akış hızını etkilemektedir (Kyte vd. 2001). Hacmin, doluluk ve hız ile olan ilişkisi yağış olaylarından etkilenmektedir. Yağış̧ı havalarda; geceleri, sadece hız azalırken; gündüzleri ise, hızın yanı sıra hacim de azalmaktadır (Unrau \& Andrey, 2006).

Sıcak hava, stres düzeyinde artış yaşanmasına ve sürücülerin performansının düşmesine neden olmaktadır (Nofal \& Saeed, 1997). Yüksek hızlı yollarda sürücü davranışları, kar yağışı ve yağmurlu havalardan olumsuz etkilenmektedir (Andrey vd. 2013). Ayrıca; kötü hava koşulları nedeniyle kapasitesinin çok altında faaliyet gösteren yollar, ekonomi üzerinde ciddi etkilere neden olmaktadır (Dey vd. 2015). Öte yandan; meteorolojik olaylar, yol güvenliği ile çarpışma ve kaza riski üzerinde negatif yönde etkilidir (J. Andrey \& Yagar, 1993; Levine vd. 1995; Andreescu \& Frost, 1998; Keay \& Simmonds, 2005; Usman vd. 2012; Jung vd. 2014; Choi \& Oh, 2016; Liu vd. 2017).

HCM 2000' de belirtildiği üzere; optimum yoğunluk düzeyleri için, genellikle C ve D seviyelerindeki yol hizmet seviyeleri kabul edilmektedir. Ayrıca; Tablo 13' deki ilk güne ait değerlerle yapılan tahmin sonuçları incelendiğinde, tahmini hız değerlerinin çoğunlukla 75- 80 aralığında olduğu görülmektedir. Buradan hareketle, Tablo 2' deki Serbest Akım Hızı kategorilerinden 80 hız düzeyi için C ve D hizmet seviyeleri incelendiğinde, Maksimum yoğunluk (araç / km / şerit) düzeyinin 16-22 aralığında, Ortalama hızın $(\mathrm{km} / \mathrm{sa})$ 77.6- 80 aralı̆̆ında, Maksimum hacim / kapasite oranının (v / c) \% 64- 85 aralığında, Maksimum servis akış hızının (araç / sa / şerit) ise 1280- 1705 araç arasında olacağı tespit edilmiştir.

Rüzgar hızı ve sıcaklık bağımsız değişkenlerinin hız üzerinde negatif yönde ve yüksek oranda; nem, mesai saatleri ve hava koşulunun pozitif yönde ve zayıf düzeyde; h.içi günlerin ise, negatif yönde ve çok zayıf bir seviyede etkisi vardır. Bağımsız değişkenlerde meydana gelecek olası bir değişme, bağımlı değişken üzerindeki etkisi oranınca yolun serbest akış hızı üzerinde de etkili olacaktır. $\mathrm{Bu}$ etkinin de hizmet seviyesi kategorisinde ve dolayısıyla da yoğunluk seviyesinde değişikliğe neden olacağ görülmüştür. 
Sıcaklık, nem ve rüzgar hızı değişkenlerinden birisinde yaşanacak olası 1 birimlik değişme sonucunda; bağımlı değişken olan hız üzerinde sıcaklığın en büyük etkiyi göstereceği, ikinci etkinin rüzgar hızındaki değişimle yaşanacağı ve nemin ise bu üç değiş̧en içerisinde en düşük düzeydeki etkiyi meydana getireceği tespit edilmiştir. Hafta içi günler içerisinde; Çarşamba günündeki olası bir değişikliğin hız üzerinde en büyük etkiyi, Perşembe günündeki olası değişimin ise en az etkiyi oluşturacağ 1 görülmüştür. Mesai saatleri içerisinde, hiz üzerinde en az etkiyi gösteren ölçüm saatinin 16:50 olduğu, 14:50' deki ölçümün ise hızda en fazla etkiyi yapacağı tespit edilmiştir. Hava koşulları içerisinde; yağmurlu havadaki 1 birimlik değişikliğin hız üzerinde en az etkinin yaşanmasına neden olacağı, güneşli havadaki değişimin ise en yüksek etkiyi yaşatacağı görülmüştür.

\section{Kaynakça}

Abdel-Aty, M., Ekram, A.-A., Huang, H., \& Choi, K. (2011). A study on crashes related to visibility obstruction due to fog and smoke. Accident Analysis \& Prevention, 43(5), 17301737. https://doi.org/10.1016/j.aap.2011.04.003

Aküzüm, Prof. Dr. T., Kodal, Doç. Dr. S., Beyribey, Doç. Dr. M., Erözel, Doç. Dr. A. Z., Tokgöz, Doç. Dr. A., Selenay, Yard. Doç. Dr. F., ... Yurtsever, Yard. Doç. Dr. E. (1994). Meteoroloji I. Ankara: Ankara Üniversitesi Ziraat Fakültesi Yayınları.

Andreescu, M. P., \& Frost, D. B. (1998). Weather and traffic accidents in montreal, Canada. Climate Research, 9(3), 225-230. https://doi.org/10.3354/cr009225

Andrey, J., \& Yagar, S. (1993). A Temporal Analysis of rain-related crash risk. Accident Analysis and Prevention, 25(4), 465-472. https://doi.org/10.1016/0001-4575(93)90076-9

Andrey, J., Hambly, D., Mills, B., \& Afrin, S. (2013). Insights into driver adaptation to inclement weather in Canada. Journal of Transport Geography, 28, 192-203. https://doi.org/10.1016/j.jtrangeo.2012.08.014

Choi, S., \& Oh, C. (2016). Proactive strategy for variable speed limit operations on freeways under foggy weather conditions. Transportation Research Record: Journal of the Transportation Research Board, 2551, 29-36. https://doi.org/10.3141/2551-04

Cools, M., Moons, E., \& Wets, G. (2007). Investigating the Effect of Holidays on Daily Traffic Counts: A Time Series. 19. https://doi.org/10.3141/2019-04

Cools, M., Moons, E., \& Wets, G. (2010). Assessing the 1mpact of weather on traffic intensity. Weather Climate and Society, 2(1), 60-68. https://doi.org/10.1175/2009WCAS1014.1

Datla, S., \& Sharma, S. (2008). Impact of cold and snow on temporal and spatial variations of highway traffic volumes. Journal of Transport Geography, 16(5), 358-372. https://doi.org/10.1016/j.jtrangeo.2007.12.003

Dey, K. C., Mishra, A., \& Chowdhury, M. (2015). Potential of intelligent transportation systems in mitigating adverse weather impacts on road mobility: a review. Ieee Transactions on Intelligent Transportation $\quad$ Systems, $16(3), \quad 1107-1119$. https://doi.org/10.1109/TITS.2014.237145

Eken, M., Ulupınar, Y., Demircan, M., Nadaroğlu, Y., Aydın, B., \& Özhan, Ü. (2008). Klimatoloji rasat el kitabı, Çevre ve Orman Bakanlığı Devlet Meteoroloji İşleri Genel Müdürlüğü. Ankara: DMİ Genel Müdürlüğü Matbaası.

Gültekin, Y., Demircan, M., Ulupınar, Y., \& Bulut, E. (2005). Klimatoloji I. Geliş tarihi gönderen https://www.mgm.gov.tr/FILES/genel/kitaplar/klimatoloji1.pdf

Haykin, S. (1998). Neural Networks A Comprehensive Foundation (Second Edition). Pearson Education. 
HCM. (2000). Highway Capacity Manual 2000. United States of America: Transportation research board, National Research Council.

Janik, M., Kurihara, O., Bossew, P., (2018). Machine Learning methods as a tool to analyse incomplete or urregularly sampled radon time series data, Sci. Total Environ., 630, 1155-1167, https://doi.org/10.1016/j.scitotenv.2018.02.233.

Jung, S., Jang, K., Yoon, Y., \& Kang, S. (2014). Contributing Factors to Vehicle to Vehicle Crash Frequency and Severity Under Rainfall. Journal of Safety Research, 50, 1-10. https://doi.org/10.1016/j.jsr.2014.01.001

Keay, K., \& Simmonds, I. (2005). The association of rainfall and other weather variables with road traffic volume in Melbourne, Australia. Accident Analysis and Prevention, 37(1), 109124. https://doi.org/10.1016/j.aap.2004.07.005

Kopal, B. (2011). Boğaziçi Köprüsü üzerindeki trafik sıkışıllı̆̆ııın hız yönetimi yöntemiyle azaltılması (Yüksek lisans tezi). Bahçeşehir Üniversitesi Fen Bilimleri Fakültesi, İstanbul.

Kyte, M., Khatib, Z., Shannon, P., \& Kitchener, F. (2001). Effect of weather on free- flow speed. traffic flow theory and highway capacity 2001: highway operations, Capacity, and Traffic Control (ss. 60-68). Transportation Research Board Natl Research Council.

Levine, N., Kim, K. E., \& Nitz, L. H. (1995). Daily fluctuations in honolulu motor vehicle accidents. Accident Analysis And Prevention, 27(6), 785-796. https://doi.org/10.1016/00014575(95)00038-0

Maind, Sonali. B., \& Wankar, P. (2014). Research paper on basic of artificial neural network |Academia.edu. International Journal on Recent and Innovation Trends in Computing and Communication, 2(1), 96-100.

Liu, A., Soneja, S. I., Jiang, C., Huang, C., Kerns, T., Beck, K., Mitchell, C., \& Sapkota, A. (2017). Frequency of extreme weather events and increased risk of motor vehicle collision in maryland, Science of The Total Environment, 580, 550-555. https://doi.org/10.1016/j.scitotenv.2016.11.211

Maze, T. H., Agarwal, M., \& Burchett, G. (2006). Whether weather matters to traffic demand, traffic safety, and traffic operations and flow. management and delivery of maintenance and operations services (ss. 170-176). Transportation Research Board Natl Research Council.

MGM. (2020). Meteoroloji Genel Müdürlüğü. https://www.mgm.gov.tr (Son Erişim: 13 Şubat 2020)

Nofal, F. H., \& Saeed, A. a. W. (1997). Seasonal variation and weather effects on road traffic accidents in riyadh city. Public Health, 111(1), 51-55. https://doi.org/10.1038/sj.ph.1900297

Öztemel, E. (2016). Yapay Sinir Ağları (4. bs). İstanbul: Papatya Yayıncılık Eğitim.

Öztürk, K., \& Şahin, M. E. (2018). Yapay sinir ağları ve yapay zekâ ýa genel bir bakış. (6/2), 25-36.

Turner, S. M., Eisele, W. L., Benz, R. J., \& Holdener, D. J. (1998). Travel time data collection handbook. texas: texas transportation institute and the texas a\&m university system.

TÜİK. (2020). Türkiye İstatistik Kurumu. http://www.tuik.gov.tr/Start.do Son Erişim: 13 Şubat 2020)

Unrau, D., \& Andrey, J. (2006). Driver Response to rainfall on urban expressways. 1çinde driver behavior, older drivers, Simulation, User Information Systems, and Visualization (ss. 24-+). Washington: Transportation Research Board Natl Research Council. 
Usman, T., Fu, L., \& Miranda-Moreno, L. F. (2012). A Disaggregate model for quantifying the safety effects of winter road maintenance activities at an operational level. Accident Analysis \& Prevention, 48, 368-378. https://doi.org/10.1016/j.aap.2012.02.005

Yan, X., Li, X., Liu, Y., \& Zhao, J. (2014). Effects of foggy conditions on drivers' speed control behaviors at different risk levels. Safety Science, 68, 275-287. https://doi.org/10.1016/j.ssci.2014.04.013

Y1lmaz, E. (2006). Karayolu trafik simülasyonu (Yüksek lisans tezi). Karadeniz Teknik Üniversitesi Fen Bilimleri Enstitüsü, Trabzon.

\section{ETİK ve BİLIMSEL İLKELER SORUMLULUK BEYANI}

$\mathrm{Bu}$ çalışmanın tüm hazırlanma süreçlerinde etik kurallara ve bilimsel atıf gösterme ilkelerine riayet edildiğini yazar(lar) beyan eder. Aksi bir durumun tespiti halinde Afyon Kocatepe Üniversitesi Sosyal Bilimler Dergisi'nin hiçbir sorumluluğu olmayıp, tüm sorumluluk makale yazarlarına aittir. 